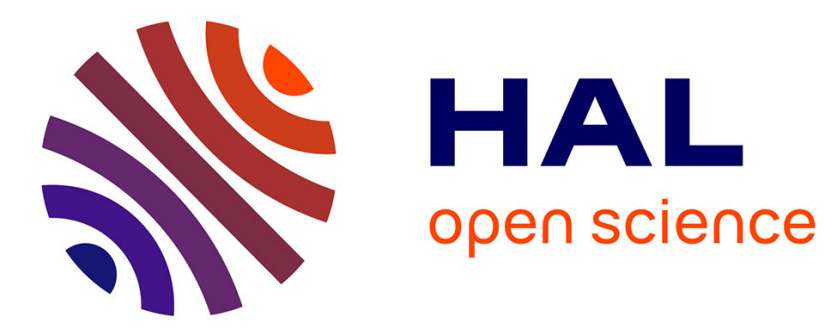

\title{
A comparison of in-cloud measurements obtained with six PMS 2D-C probes
}

\author{
J. F. Gayet, Philip R. A. Brown, Frank Albers
}

\section{To cite this version:}

J. F. Gayet, Philip R. A. Brown, Frank Albers. A comparison of in-cloud measurements obtained with six PMS 2D-C probes. Journal of Atmospheric and Oceanic Technology, 1993, 10 (2), pp.180-194. 10.1175/1520-0426(1993)0102.0.CO;2 . hal-01989658

\section{HAL Id: hal-01989658 \\ https://hal.uca.fr/hal-01989658}

Submitted on 3 Feb 2021

HAL is a multi-disciplinary open access archive for the deposit and dissemination of scientific research documents, whether they are published or not. The documents may come from teaching and research institutions in France or abroad, or from public or private research centers.
L'archive ouverte pluridisciplinaire HAL, est destinée au dépôt et à la diffusion de documents scientifiques de niveau recherche, publiés ou non, émanant des établissements d'enseignement et de recherche français ou étrangers, des laboratoires publics ou privés. 


\title{
A Comparison of In-Cloud Measurements Obtained with Six PMS 2D-C Probes
}

\author{
JEAN-FrançOIS GAYET \\ University Blaise Pascal, Clermont-Ferrand, France \\ PHILIP R. A. BROWN \\ Meteorological Research Flight. Farnborough, United Kingdom \\ FRANK ALBERS \\ GKSS Research Centre, Institute for Physics, Geesthacht, Federal Republic of Germany \\ (Manuscript received 9 October 1991, in final form 20 April 1992)
}

\begin{abstract}
During a preparatory experiment (PREICE) for the field campaign of the International Cirrus Experiment (ICE), six different Particle Measuring Systems (PMS) 2D-C probes belonging to five research organizations were intercompared. Three of these probes were original versions (2D-C), the three others being updated instruments (2D2-C version). The comparisons were performed using data obtained during flights in various types of warm and glaciated clouds.

The probe-by-probe comparisons show that relative particle-size response is in good agreement for all the probes and a variety of particle shapes. Similarly, measurements of the mean volume particle size agree to within about $10 \%$. There are, however, noticeable discrepancies up to a factor of about 1.5 in values of the particle concentration. This can lead to similar large uncertainties in values of derived parameters, such as ice water content (IWC) and extinction coefficient. These differences are found to be related primarily to the probe version; the updated 2D2-C instruments appear to detect some 50\% more images than the original version (2D-C).

Large differences may also be obtained when two different but common methods of calculation of the sample time are applied to data from a single probe. This appears to be related to timing errors within the probe data stream. There is a need for the standardization of processing schemes, where possible, in order to reduce the uncertainties in results obtained during multiaircraft cooperative experiments.
\end{abstract}

\section{Introduction}

Cirrus clouds are thought to be an important modulator of the global climate (see, for example, Cox 1973; Stephens and Webster 1981). Stephens et al. (1990) show that the feedback effect of cirrus on climate can be positive or negative depending on the microphysical and scattering properties of the cloud. Slingo (1990), in a study of the sensitivity of a global climate model to variations in the cloud properties, has highlighted the need for an understanding of the limits of accuracy of in situ measurements.

In order to obtain improved knowledge of the microphysical, dynamical, and radiative transfer properties of cirrus, the International Cirrus Experiment (ICE) was established by research groups from France, the Federal Republic of Germany, the United King-

Corresponding author address: Jean-François Gayet, Laboratoire de Meteorologie Physique, Universite Blaise Pascal-C.N.R.S., Observatoire de Physique du Globe, 12, avenue des Landais, 63000 Clermont-Ferrand, France. dom, and Sweden (Raschke et al. 1990) as a regional experiment within the scope of the International Satellite Cloud Climatology Project (ISCCP). The intensive field phase of this experiment was planned to include several aircraft equipped with similar microphysics instruments [two-dimensional optical array probes (2D-C) manufactured by Particle Measuring Systems, Inc. (PMS)]. In order to intercompare data from the different probes to be used during the main experiment, a preparatory experiment (PREICE) was performed from the Centre d'Essais en Vol (Brétigny, France) during the period 23 January-3 March 1989.

The purpose of this paper is to describe the main results obtained by mounting up to four probes simultaneously on the research aircraft, using a single method of data processing. In addition, we examine some effects of changes in true airspeed and mounting location on the aircraft, and also the differences in processed results obtained by using two different samplingtime determinations on the same dataset.

As well as being relevant to data analysis for ICE and similar experiments elsewhere, the results indicate 


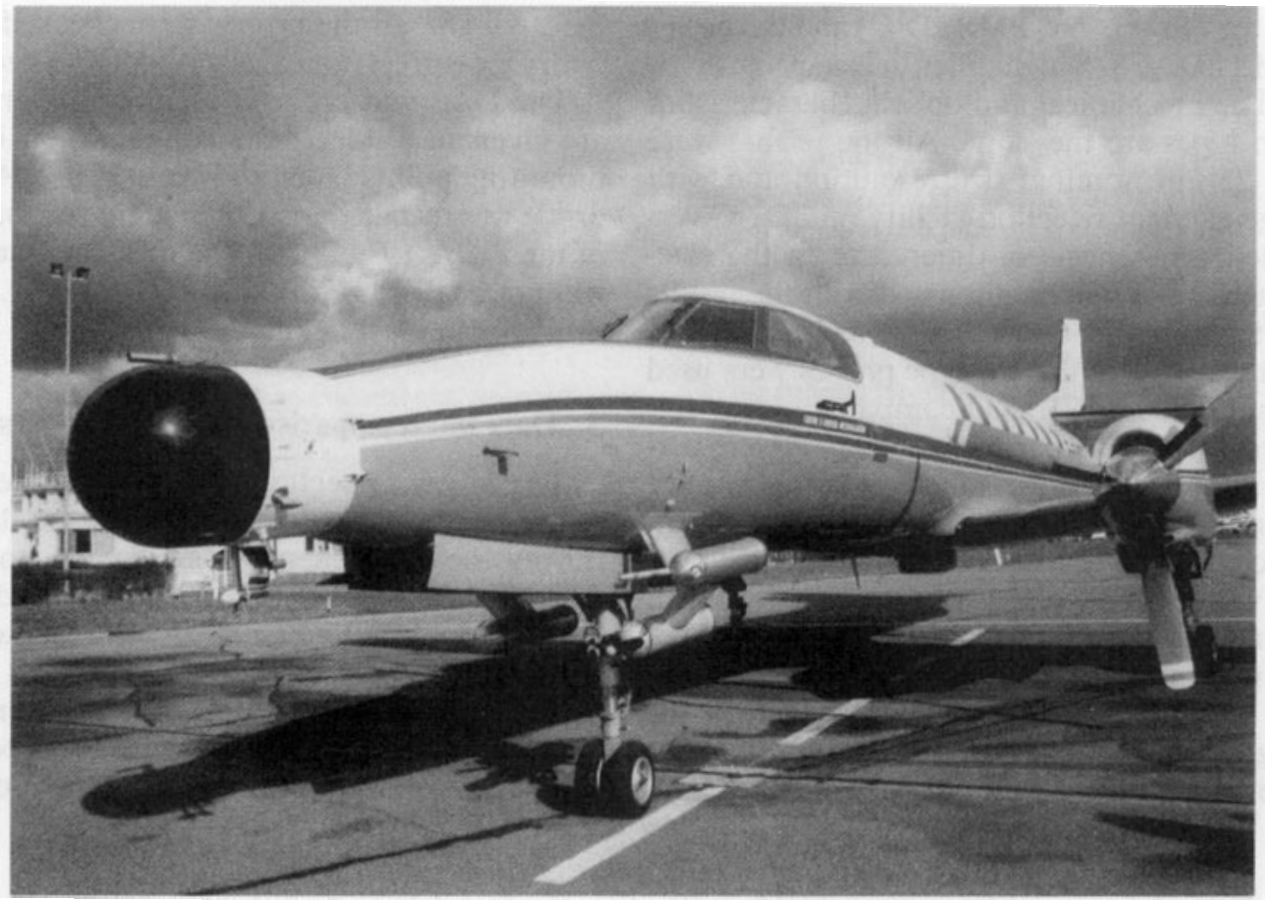

FIG. 1. The Merlin IV of the Centre d'Aviation Météorologique, showing the mounting location for PMS probes beneath the nose. (Courtesy of the French Meteorological Research Center: Météorologie Nationale, EERM/PAD.)

the limitations on in situ measurement accuracy and hence, as noted above, on the reliability of current parameterization of clouds in global climate models.

\section{The PREICE experiment}

The aircraft used was the Merlin IV operated by the Centre d'Aviation Météorologique (CAM, a division of the French Weather Service) based in Brétigny. This aircraft is equipped with conventional thermodynamical, dynamical, and navigation instruments (Guillemet 1990). Depending on the purpose of the flight, additional measurements of radiative fluxes or microphysical parameters may be made. During the PREICE experiment, four $2 \mathrm{D}-\mathrm{C}$ probes were mounted on pylons grouped beneath the nose of the aircraft (Fig. 1). The data from two of the probes were recorded via the main aircraft data acquisition system (DAS) designed by the CAM, data from the other two being recorded by a PMS DAS-32 system from the University of Cologne. These two data acquisition systems will hereafter be referred to as the "aircraft DAS" and the "PMS DAS," respectively. Six PMS 2D-C probes were operated during the experiment. They were provided by the following organizations:

- Meteorological Office, Meteorological Research Flight (MRF), Farnborough, United Kingdom;

- GKSS Research Centre, Institute for Physics,
Geesthacht, Federal Republic of Germany (two probes, formerly operated by the University of Cologne);

- Centre d'Aviation Météorologique (CAM), Brétigny, France;

- Institut National des Sciences de l'Univers (INSU), France;

- Laboratoire de Météorologie Physique (LaMP), Clermont-Ferrand, France.

In this paper, individual 2D-C probes will not be identified by organization and will hereafter be referred to as probes P1-P6. The specifications of these probes are shown in Table 1. They can be classified into two

TABLE 1. Main characteristics of the PMS 2D-C probes analyzed and compared in this study.

\begin{tabular}{ccccc}
\hline \hline Probe & $\begin{array}{c}\text { Purchase } \\
\text { year }\end{array}$ & $\begin{array}{c}\text { Manufacturer } \\
\text { version* }\end{array}$ & $\begin{array}{c}\text { Photodiode } \\
\text { response } \\
\text { time }\end{array}$ & $\begin{array}{c}\text { Buffer } \\
\text { memory } \\
\text { access }\end{array}$ \\
\hline P2 & 1989 & PMS 2D2-C & $0.3 \mu \mathrm{s}$ & Random \\
P4 & 1988 & PMS 2D2-C & $0.3 \mu \mathrm{s}$ & Random \\
P6 & 1987 & PMS 2D2-C & $0.3 \mu \mathrm{s}$ & Random \\
P1 & 1982 & PMS 2D-C & N/A** & Shift register \\
P5 & 1980 & PMS 2D-C & N/A & Shift register \\
P3 & 1980 & PMS 2D-C & $1.0 \mu \mathrm{s}$ & Shift register \\
\hline
\end{tabular}

* These versions correspond to probes having 32 photodiodes with a nominal size resolution of $25 \mu \mathrm{m}$.

** N/A indicates that the measurement is not available. 
main types, the old version (PMS 2D-C) and the newer version (PMS 2D2-C), which differ in electronic characteristics. The mechanical and optical characteristics of these two types are the same. All the probes were operated at $25-\mu \mathrm{m}$ nominal size resolution and with the new edge-element rejection facility on 2D2-C versions disabled. The effects of differences in the electronic characteristics will be discussed with the results of probe intercomparisons in section 5 . It should be noted here that none of the old-type probes were used during the subsequent ICE field campaign.

During the PREICE experiment six flights were performed in various types of warm and glaciated clouds, including stratocumulus, embedded convective clouds, altostratus, cirrus, and cirrostratus. Both water droplets and a wide variety of ice-crystal shapes were sampled, as summarized in Table 2. A typical flight consisted of measurement runs in cloud regions as homogeneous as possible at several different airspeeds within the overall range from 80 to $130 \mathrm{~m} \mathrm{~s}^{-1}$. A total of about four hours of in-cloud data were obtained and analyzed.
Before flight, all the probes were checked in the laboratory for correct optical alignment and size calibration.

The DAS and probe configurations on the aircraft are given in Table 2, the configuration of the probe mounting points being shown in Fig. 2. A PMS 1D-C probe was installed instead of a $2 \mathrm{D}$ version during two of the flights (Table 2). The measurements from this will not be discussed in the present paper, but they are available in Gayet et al. (1990).

\section{Data intercomparisons-General considerations}

The following sections will be illustrated with some specific examples selected from all the data recorded during the experiment. A systematic analysis of the whole dataset (Gayet et al. 1990), however, has shown these examples to be representative of the whole.

For the purpose of clarity, the probe 1 was selected as a reference against which all others were compared. This was a $2 \mathrm{D}-\mathrm{C}$ model type and was operated in the same mounting point and DAS configuration

TABLE 2. Summary of the probe and DAS configurations experienced during the flights. Cloud types, main sampled particle habits, temperature ranges, and in-cloud durations are also indicated.

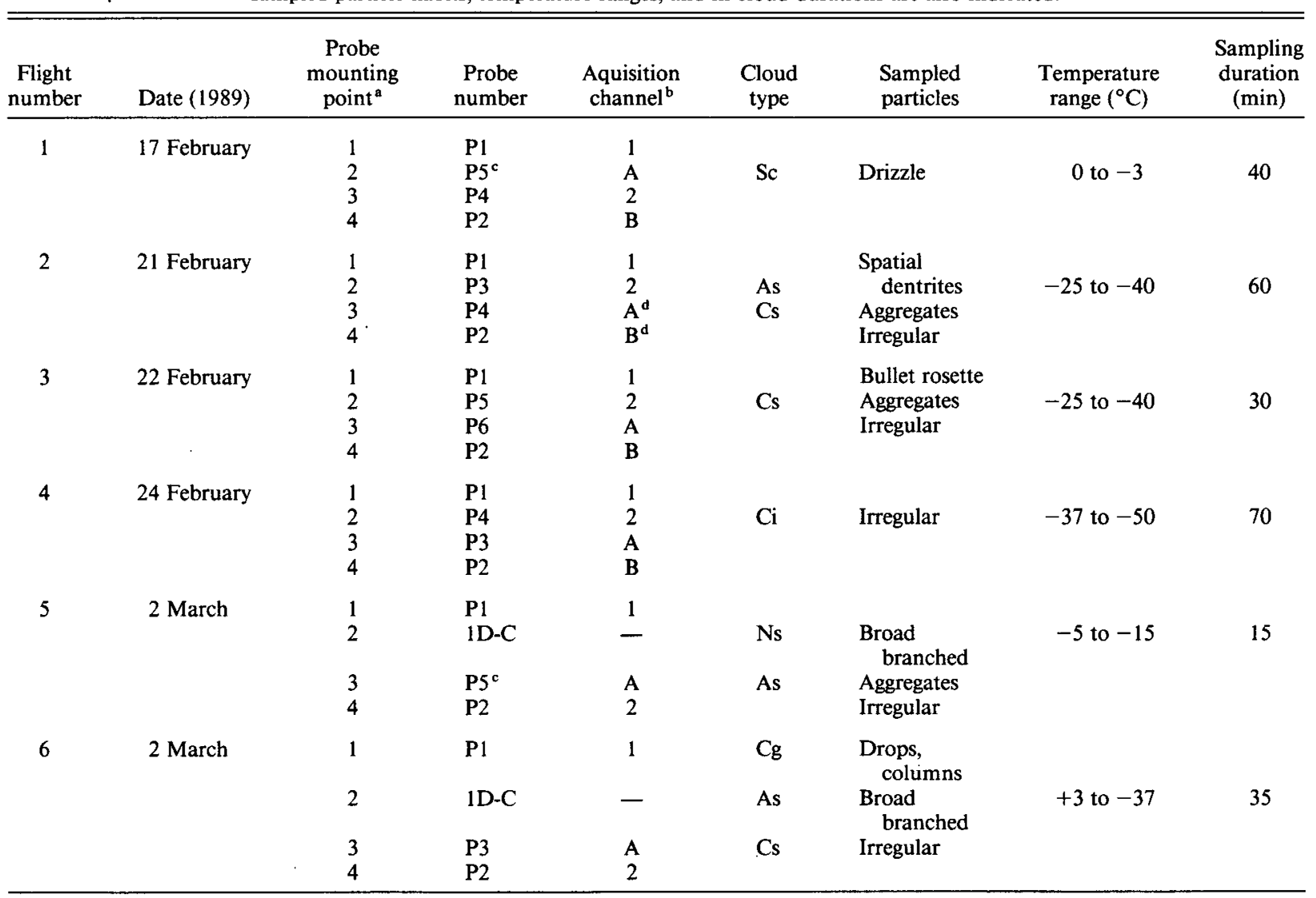

${ }^{a}$ Numbers 1-4 refer to the probe mounting points indicated in Fig. 2.

b Numbers 1 and 2 refer to the aircraft DAS, and letters A and B to the PMS DAS channels, respectively.

${ }^{c}$ Probe not working during the whole flight.

d DAS system operated for only a few minutes. 


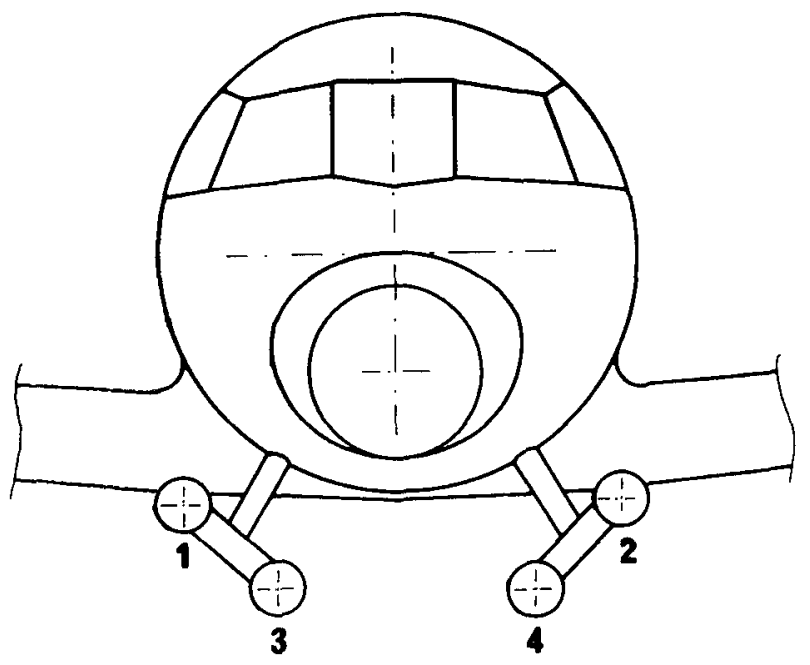

FIG. 2. Schematic view of the Merlin IV looking from in front of the aircraft, showing the four probe mounting locations. These locations are $2.8 \mathrm{~m}$ ahead of the propeller disk.

throughout the whole experiment. Further, a single method of data processing was employed to eliminate software effects in the comparison of different probes. This method provides the size spectrum distributed over 30 channels, each having a $25-\mu \mathrm{m}$ resolution ( $25-$ $750-\mu \mathrm{m}$ size range), at $1-\mathrm{Hz}$ frequency. The primary sizing parameter used for all particle images is the mean diameter, that is, the mean value of the image dimensions measured parallel and perpendicular to the orientation of the photodiode array. The sample volume is the product of the sample area, the sampling time, and the true airspeed. The sample area is itself the product of the depth of field (DoF) and the effective sample width (ESW) (Heymsfield and Baumgardner 1985, hereafter HB). During the present study, the DoF used for each probe was obtained from values given in the original user manual of the probe being processed. These are shown in Table 3. Heymsfield and Baumgardner, however, have shown that the DoF for individual probes may differ substantially from the theoretical values originally proposed by Knollenberg (1970). This suggests that there may be some uncertainty in the DoF values used, particularly for ice particles.

Before the presentation of the results of the probeby-probe intercomparison, we first discuss the magnitude of errors caused by the use of different probe mounting locations and different data acquisition systems.

\section{a. Probe mounting location}

Distortion of the airflow around aircraft structures can affect measurements made with externally mounted probes. Theoretical studies ( see, for example, King 1984) have illustrated the effects of the local flow field at different locations around the aircraft on particle size and concentration measurements. Airflow model predictions have also been verified by means of a podmounted pitot-static sensor designed by the National Research Council in Ottawa (MacPherson and Baumgardner 1988). Such investigations have not yet been carried out for the Merlin nose-mounted PMS probes. Nevertheless, the possible effects of the aircraft flow field at the different mounting locations can be estimated from the analysis of data obtained from various different probe combinations. Figure 3 illustrates the concentrations of particles measured by the probe 4 , which was first mounted in position 2 (upper right looking toward the nose from in front of the aircraft) and then in position 3 (lower left, see Table 2 and Fig. 2 ). These concentrations are plotted against the concentration of the reference probe 1 (position 1). For one of these periods ( flight 1 ), the aircraft flew in stratocumulus with drizzle drops being observed, while for the other (flight 4), cirrus containing irregular crystals was sampled. Despite these differences in the particle type, the best-fit equation curves show that concentra-

TABLE 3. Channel number, mean particle size, and sampling surface values of each probe considered in the present study.

\begin{tabular}{|c|c|c|c|c|}
\hline \multirow[b]{2}{*}{$\begin{array}{l}\text { Channel } \\
\text { number }\end{array}$} & \multirow[b]{2}{*}{$\begin{array}{c}\text { Mean size } \\
(\mu \mathrm{m})\end{array}$} & \multicolumn{3}{|c|}{ Sampling surfaces $\left(\mathrm{mm}^{2}\right)$} \\
\hline & & $\begin{array}{l}\text { P5 } \\
\text { P3 }\end{array}$ & $\mathbf{P l}$ & $\begin{array}{l}\text { P2 } \\
\text { P4 } \\
\text { P6 }\end{array}$ \\
\hline 1 & 25 & 1.170 & 0.442 & 1.701 \\
\hline 2 & 50 & 4.531 & 3.385 & 5.457 \\
\hline 3 & 75 & 9.842 & 9.874 & 8.728 \\
\hline 4 & 100 & 16.875 & 18.380 & 18.380 \\
\hline 5 & 125 & 25.389 & 27.090 & 27.090 \\
\hline 6 & 150 & 35.156 & 36.940 & 36.940 \\
\hline 7 & 175 & 36.600 & 36.600 & 36.600 \\
\hline 8 & 200 & 35.075 & 35.075 & 35.075 \\
\hline 9 & 225 & 33.550 & 33.550 & 33.550 \\
\hline 10 & 250 & 32.025 & 32.025 & 32.025 \\
\hline 11 & 275 & 30.500 & 30.500 & 30.500 \\
\hline 12 & 300 & 28.975 & 28.975 & 28.975 \\
\hline 13 & 325 & 27.450 & 27.450 & 27.450 \\
\hline 14 & 350 & 25.925 & 25.925 & 25.925 \\
\hline 15 & 375 & 24.400 & 24.400 & 24.400 \\
\hline 16 & 400 & 22.875 & 22.875 & 22.875 \\
\hline 17 & 425 & 21.350 & 21.350 & 21.350 \\
\hline 18 & 450 & 19.825 & 19.825 & 19.825 \\
\hline 19 & 475 & 18.300 & 18.300 & 18.300 \\
\hline 20 & 500 & 16.775 & 16.775 & 16.775 \\
\hline 21 & 525 & 15.250 & 15.250 & 15.250 \\
\hline 22 & 550 & 13.725 & 13.725 & 13.725 \\
\hline 23 & 575 & 12.200 & 12.200 & 12.200 \\
\hline 24 & 600 & 10.675 & 10.675 & 10.675 \\
\hline 25 & 625 & 9.150 & 9.150 & 9.150 \\
\hline 26 & 650 & 7.625 & 7.625 & 7.625 \\
\hline 27 & 675 & 6.100 & 6.100 & 6.100 \\
\hline 28 & 700 & 4.575 & 4.575 & 4.575 \\
\hline 29 & 725 & 3.050 & 3.050 & 3.050 \\
\hline 30 & 750 & 1.525 & 1.525 & 1.525 \\
\hline
\end{tabular}




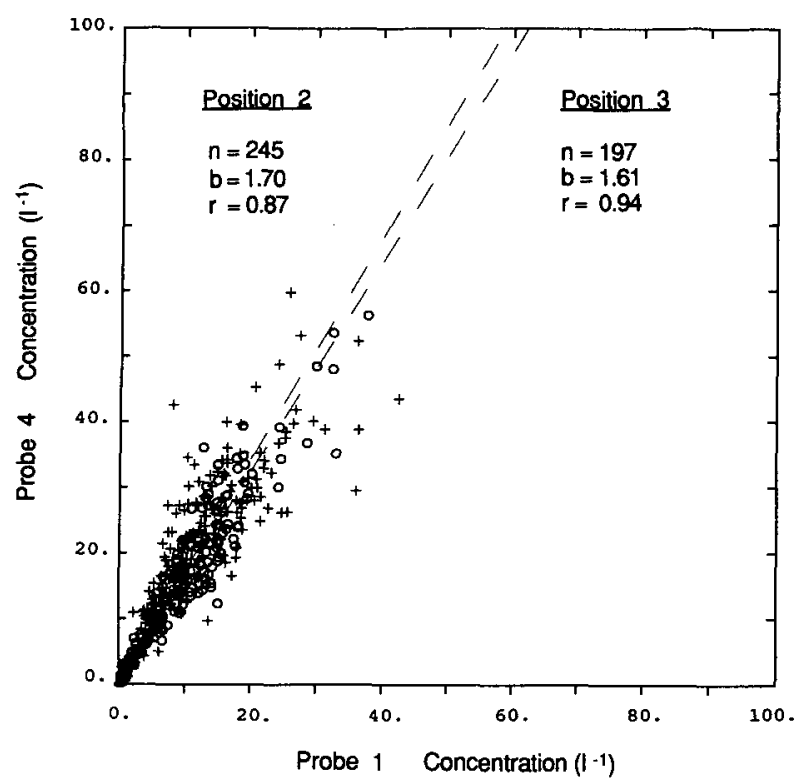

FIG. 3. Comparison of the particle concentration obtained from probe 4 and probe 1 . Crosses represent measurements obtained by probe 4 mounted in position 2 ; circles represents measurements obtained with the same probe mounted in position 3 (see Fig. 2). The symbols $n, b$, and $r$ refer to the number of data points, the slope of the best-fit curve equation, and the correlation coefficient, respectively.

tion measurements from probe P4 agree to within 5\% on both occasions.

The mounting location would be expected to affect both concentration measurements and particle orientation through distortion and shear of the airflow in the vicinity of the probe sampling region (Baumgardner 1983a). The orientation of ice columns (see Fig. 4a) measured by probes in positions 1 and 3 (upper and lower left) on flight 6 are reported on Figs. $4 \mathrm{~b}$ and $4 \mathrm{c}$, respectively. The results show a strong preferential orientation that has a mode value near $0^{\circ}$ for both positions. Thus, the major axes of columnar crystals are mainly orientated parallel to the direction of flight.

The concentration differences between probes $\mathrm{P} 4$ and $\mathrm{P} 1$, when both are mounted in the upper mounting positions ( 2 and 1 ), do not differ significantly from the values obtained when probe $\mathrm{P} 4$ is mounted in a lower position (3). It therefore seems reasonable to assume that the differences are due primarily to the probes themselves rather than to any effect of the different mounting locations. This is confirmed by the crystal-orientation measurements, which also show no significant differences between upper and lower mounting locations. It should be noted here that all the data considered in this section were obtained during periods of straight and level flight. Given the left-toright symmetry of the four mounting points, there should therefore be no observable difference between the two upper or lower mounting points. This would not necessarily be expected to apply for any data obtained during turns or asymmetric flight.

\section{b. Data acquisition systems}

As described earlier, two different DAS systems were in use simultaneously. The aircraft-DAS clock is slaved to the aircraft true airspeed, whereas the PMS-DAS clock was manually set to $4 \mathrm{MHz}$ (which corresponds to a nominal airspeed of $100 \mathrm{~m} \mathrm{~s}^{-1}$ ). Consequently, the particle-size measurements, made with probes recorded via the PMS DAS, needed to be corrected for differences between the actual true airspeed and the nominal value. Since it was not possible to change the probe-DAS connections during a single flight, results necessary to examine the possible effects of each DAS on the data from a particular probe had to be assembled over different flights. Figure 5 shows measurements of particle concentration made by probe 2 when used with both the aircraft DAS and PMS DAS, relative to measurements from the reference $\mathrm{Pl}$, which was recorded via the aircraft DAS. There is reasonable agreement in the slopes of the best-fit equation curves (1.11 against 1.27 ). This suggests that the two DAS systems, which have different timing processes and data formats, provide information from which the particle concentration can be obtained to within an accuracy of $15 \%$. This is no larger than the standard deviation due to the in-
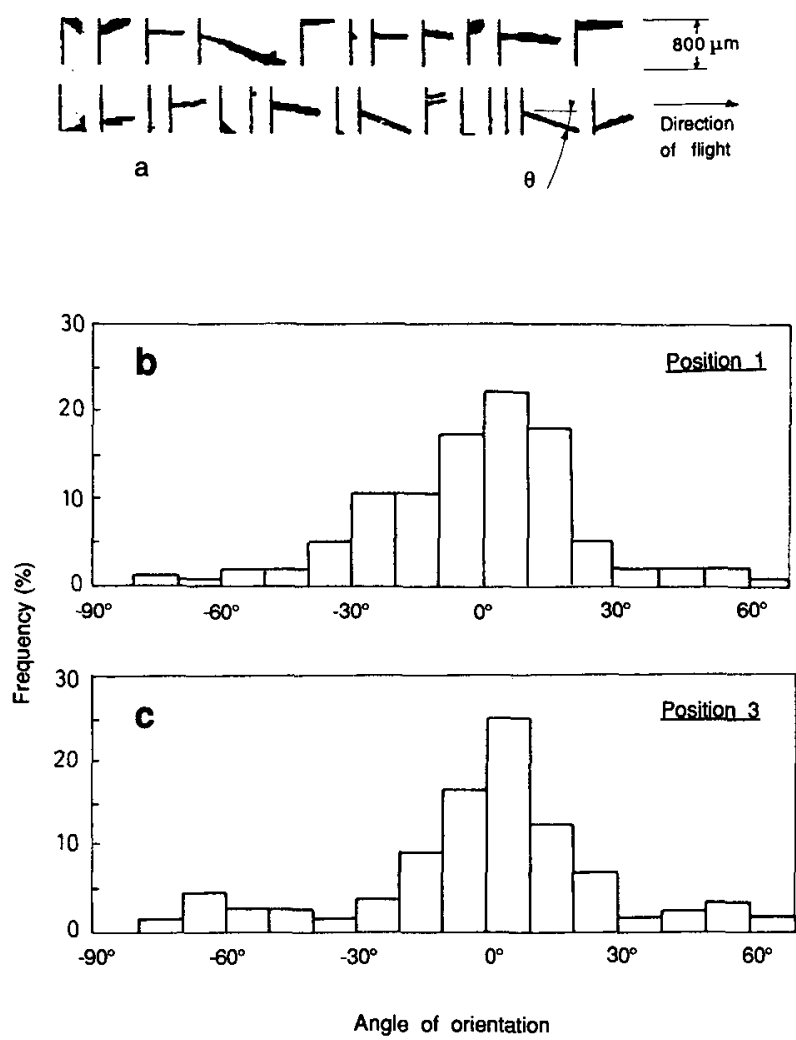

FIG. 4. (a) Example of ice-column images obtained by probe 1 mounted in position 1 indicating the definition of the angle of orientation $\theta$ (from Baumgardner 1983a). (b) and (c) Histograms of the angle of orientation of ice columns observed during flight 6 in positions 1 and 3 , respectively. 


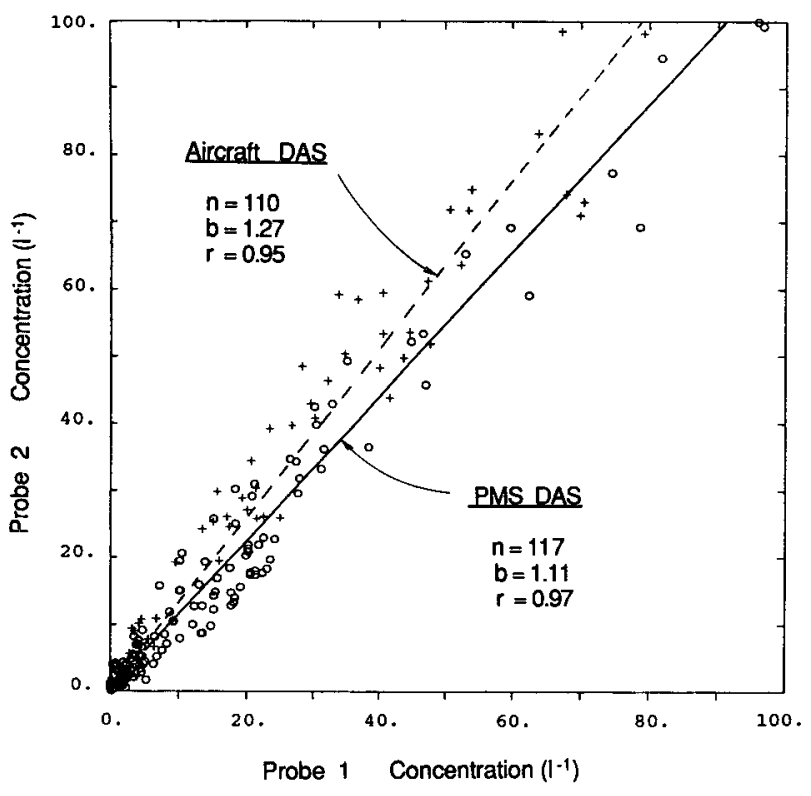

FIG. 5. Comparison of the particle concentration obtained from probe 2 and probe 1 . Crosses represent measurements obtained by probe 2 with the aircraft DAS, circles represent measurements obtained with the PMS DAS. The corresponding best fits are also represented.

strument errors $(25 \%-30 \%)$, which will be discussed in section 5 .

\section{Results of the probe-by-probe intercomparison}

Having quantified the errors on measurements due to the use of different data recording systems and probe mounting locations, we now proceed to the intercomparison analysis between individual probes, with particular reference to the model type P1. Each probe-byprobe intercomparison is presented in terms of slope and intercept parameters and linear regression coefficient. According to the regression analysis proposed by Baumgardner (1983b), the least-squares fit to the data was calculated by minimizing the perpendicular distance from each point to the fitted line. Each data point represents a 5-s mean value, and the regression line is forced through zero when comparing concentration measurements. For the purpose of this study, the bestfit line and the regression coefficient are used as means of illustrating the agreement between the two measurements and of indicating the scatter in the observed data. The differences from one-to-one agreement in the measurements will be interpreted as systematic errors, whereas the observed scatter about the general trend will reflect random errors.

The results of these linear regression analyses are all summarized in Table 4. A blank entry in this table indicates that the particular combination of probes and airspeed ranges was not able to be examined from the data that were obtained during the six flights.

\section{a. Particle concentration}

We refer to measurements in three size ranges of the concentrations $\mathrm{Cs}, \mathrm{Cm}$, and $\mathrm{Cl}$ of particles larger than 50,100 , and $150 \mu \mathrm{m}$, respectively. We do not consider measurements in the smallest size channel $(25 \mu \mathrm{m})$, as these are known to have large uncertainties (see, for example, Gordon and Marwitz 1984).

TABLE 4. Summary of the statistical results on particle concentration and mean volume size for each probe referenced to probe 1.

\begin{tabular}{|c|c|c|c|c|c|c|c|c|c|c|c|c|}
\hline \multirow[b]{3}{*}{ Probe } & \multirow{3}{*}{$\begin{array}{c}\text { Airspeed } \\
\text { range* }\end{array}$} & \multicolumn{6}{|c|}{ Particle concentration } & & & & & \\
\hline & & \multicolumn{2}{|c|}{ Cs } & \multicolumn{2}{|c|}{$\mathrm{Cm}$} & \multicolumn{2}{|c|}{$\mathrm{Cl}$} & \multicolumn{3}{|c|}{ Mean volume size } & \multirow[b]{2}{*}{$n$} & \multirow{2}{*}{$\begin{array}{c}\text { Flight } \\
\text { number }\end{array}$} \\
\hline & & $b$ & $r$ & $b$ & $r$ & $b$ & $r$ & $a_{0}$ & $b$ & $r$ & & \\
\hline \multirow[t]{3}{*}{$\mathrm{P} 2$} & 1 & 1.24 & .94 & 1.67 & .93 & 1.98 & .92 & 4 & 1.03 & .84 & 98 & \\
\hline & 2 & 1.37 & .97 & 1.54 & .96 & 1.61 & .94 & 6 & 1.03 & .83 & 170 & 6 \\
\hline & 3 & 1.39 & .97 & 1.82 & .93 & 1.97 & .90 & 29 & 0.90 & .88 & 80 & \\
\hline \multirow[t]{3}{*}{ P4 } & 1 & 1.20 & .96 & 1.61 & .95 & 1.64 & .95 & 17 & 0.98 & .96 & 182 & \\
\hline & 2 & 1.34 & .98 & 1.87 & .92 & 1.67 & .96 & 22 & 0.93 & .95 & 229 & 1 \\
\hline & 3 & 1.30 & .96 & 1.71 & .95 & 2.05 & .80 & 9 & 1.05 & .95 & 27 & \\
\hline \multirow[t]{3}{*}{ P6 } & 1 & - & - & - & - & - & - & - & - & - & - & \\
\hline & 2 & 0.86 & .93 & 0.97 & .87 & 0.87 & .81 & -14 & 1.04 & .84 & 164 & 3 \\
\hline & 3 & - & - & - & - & - & - & - & - & - & - & \\
\hline \multirow[t]{3}{*}{ P5 } & 1 & - & - & - & - & - & - & - & - & - & - & \\
\hline & 2 & 0.82 & .90 & 0.91 & .97 & 0.86 & .95 & -13 & 1.03 & .95 & 292 & 3 \\
\hline & 3 & - & - & - & - & - & - & - & - & - & - & \\
\hline \multirow[t]{3}{*}{ P3 } & 1 & 1.14 & .78 & 1.05 & .80 & 1.03 & .87 & -30 & 1.09 & .66 & 72 & \\
\hline & 2 & 0.88 & .90 & 1.04 & .92 & 1.03 & .83 & 24 & 0.92 & .80 & 377 & 2 \\
\hline & 3 & 0.73 & .85 & 0.86 & .85 & 0.94 & .80 & 32 & 0.89 & .73 & 153 & \\
\hline
\end{tabular}

* The numbers 1, 2, and 3 refer to measurements obtained for airspeeds that ranged from 80 to 90,90 to 110 , and 110 to $130 \mathrm{~m} \mathrm{~s}^{-1}$ respectively. The symbols $a_{0}, b, r$, and $n$ refer to the intercept parameter, the slope parameter, the correlation coefficient, and the number of data points, respectively. The regression line is forced through zero $\left(a_{0}=0\right)$ when comparing measurements of particle concentration. 

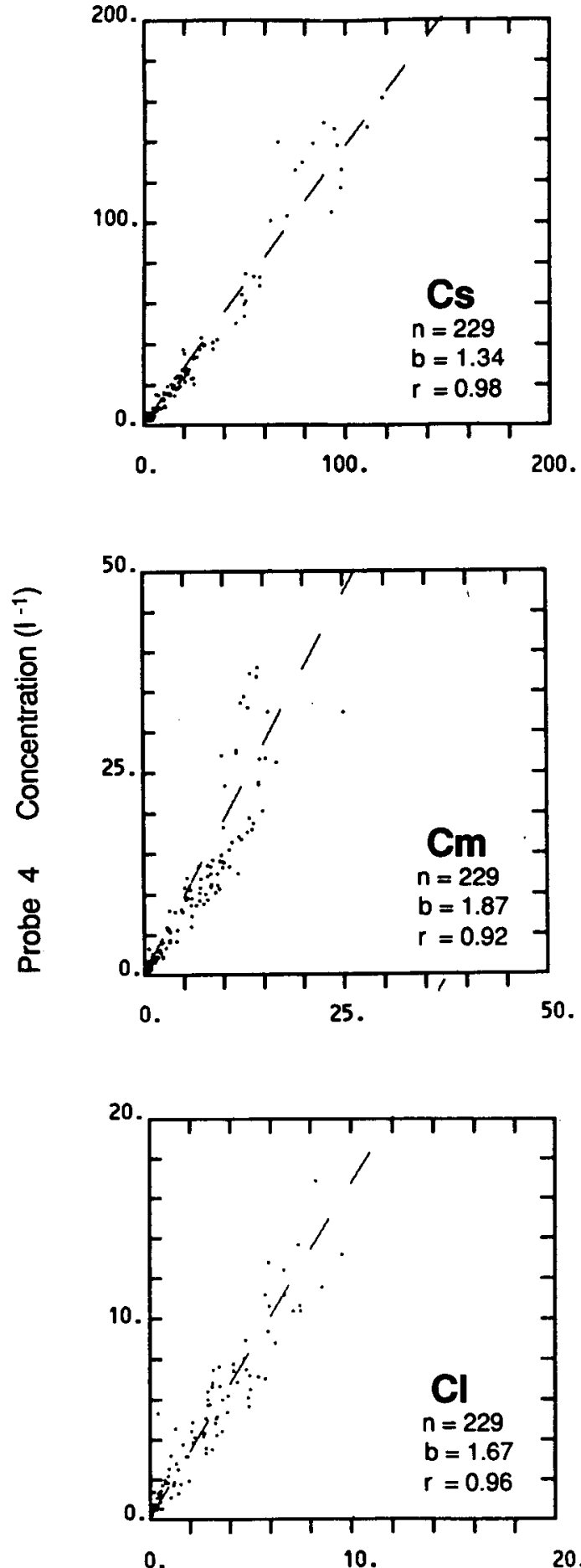

Probe 1 Concentration $\left(\left(^{-1}\right)\right.$

FIG. 6. Comparison of the particle concentrations obtained from probe 4 and probe 1 for three size ranges: Cs $(50-750 \mu \mathrm{m}), \mathrm{Cm}$ $(100-750 \mu \mathrm{m})$, and $\mathrm{Cl}(150-750 \mu \mathrm{m})$ at an airspeed of $100 \mathrm{~m} \mathrm{~s}^{-1}$ $\pm 10 \%$. The particles samples were drizzle drops in the stratocumulus cloud at temperature near $0^{\circ} \mathrm{C}$.
1) RESUlTS OBTAINED AT NOMINAL AIRSPEED OF $100 \mathrm{~m} \mathrm{~s}^{-1}$

For data obtained at an airspeed of between 90 and $110 \mathrm{~m} \mathrm{~s}^{-1}$, representative results are shown in Figs. 6 and 8 and Table 4, and the full results may be summarized as follows.

1) For every probe, and for each of the three size ranges, a linear relationship is found between the concentration measurements made by the probe being tested and probe 1 . The linear correlation coefficient is generally greater than 0.90 , which reflects a small scatter about the best-fit line. Furthermore, the coefficient of variation (the ratio of the standard deviation about the best-fit line to the mean) does not change significantly when the concentration increases. Table 5 illustrates the values of this coefficient when comparing probe 2 and probe 1 . It is of the order of $25 \%$ for particle concentration ranging from 10 to $120 \mathrm{l}^{-1}$. Similar values are found for the other probes. One example of concentration intercomparison is displayed in Fig. 6 (probe 4 versus reference probe 1). The data were obtained at a temperature near $0^{\circ} \mathrm{C}$ in a stratocumulus cloud (flight 1 ) in which drizzle drops of up to about $400 \mu \mathrm{m}$ in diameter were observed. The corresponding mean-size spectra for these two probes for the same time period are displayed in Fig. 7.

2) For each probe, the values of the slope parameter $b$ appear to be systematically lower for the smaller size concentration (Cs) than for the larger size ranges $(\mathrm{Cm}$ and $\mathrm{Cl}$ ). For example (see Table 4 ), $b=1.37$ for Cs against 1.54 and 1.61 for $\mathrm{Cm}$ and $\mathrm{Cl}$, respectively (probe 2). This can be explained by the fact that the value of the sampling surface (for a mean size of 50 $\mu \mathrm{m}$ ) of the reference probe 1 is smaller than the values of the other probes (see Table 3). For larger particle size, the sampling surfaces are similar.

3) The regression parameters can also be related to the probe type. Two of the new version probes ( $\mathrm{P} 2$ and P4) overestimate the particle concentration relative to Pl by similar factors when considering each size range. For example, the Cs slope parameters are 1.37 and 1.34 for P2 and P4, respectively. On the other hand, despite the fact that the probe 6 is a new version, it

TABLE 5. Coefficient of variation $(\sigma / \overline{\mathrm{Cs}})$ as a function of five different ranges of particle concentration $(\overline{\mathrm{Cs}})$. Here $\sigma$ is the standard deviation about the best-fit line (comparison between probe 2 and probe 1).

\begin{tabular}{ccc}
\hline \hline$\overline{\mathrm{Cs}}\left(1^{-1}\right)$ & $\sigma\left(1^{-1}\right)$ & $\sigma / \overline{\mathrm{Cs}}(\%)$ \\
\hline 10 & 3.2 & 32 \\
37 & 9.9 & 27 \\
46 & 10.0 & 22 \\
87 & 22.0 & 25 \\
118 & 30.4 & 26 \\
\hline
\end{tabular}




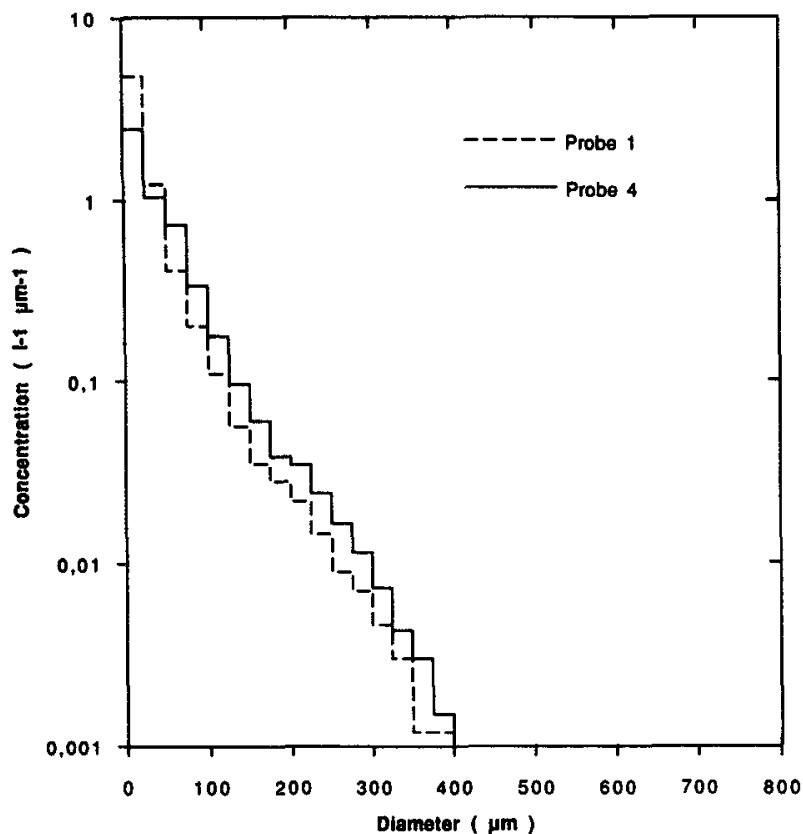

FIG. 7. Particle-size spectra obtained simultaneously by the two probes 4 and 1, as in Fig. 6 .

gives a similar response to probe 5 and probe 3 (2D$C$ version). In fact, the relative concentration responses of these three probes are similar when considering the three size ranges. They reflect an underestimation factor of about $15 \%$ for the smaller size range (the Cs slope parameters range from 0.82 to 0.88 ). This result is illustrated in Fig. 8, where the particle concentrations simultaneously measured by the probes 6 and 1 are reported. The data were obtained at a temperature of $-37^{\circ} \mathrm{C}$ in cirrostratus cloud associated with a warm front (flight 3 ) in which the ice crystals were mostly of the bullet rosette form.

\section{2) EFFECT OF THE AIRSPEED ON THE CONCENTRATION MEASUREMENTS}

The effect of the airspeed was different for the different probes. Figure 9 shows the comparison of concentration measurements from probe 2 with those from the reference probe 1 . The comparison is shown for the three size ranges defined earlier and for three ranges of true airspeed (TAS): (a) $80<$ TAS $<90 \mathrm{~m} \mathrm{~s}^{-1}$, (b) $90<$ TAS $<110 \mathrm{~m} \mathrm{~s}^{-1}$, and (c) $110<$ TAS $<130$ $\mathrm{m} \mathrm{s}^{-1}$. The data were obtained at a range of temperatures between $+3^{\circ}$ and $-37^{\circ} \mathrm{C}$ in convective clouds containing water drops and ice columns, and then in altostratus and cirrus clouds containing mostly irregular ice particles (flight 6 ). The results show that the probe overcounts (compared with probe 1), for particles larger than $50 \mu \mathrm{m}$, by a factor that does not appear to vary significantly as a function of the airspeed (1.30
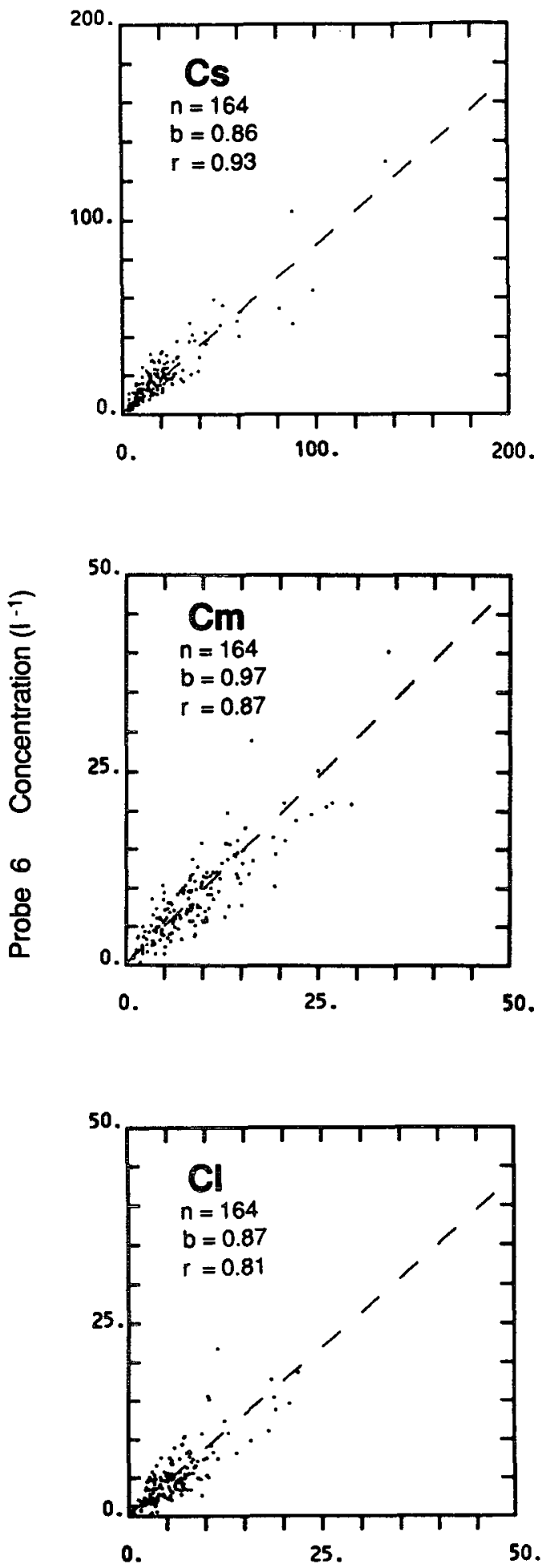

\section{Probe 1 Concentration $(\mid-1)$}

Fig. 8. As Fig. 6 but plotting probe- 6 data against data from probe 1. The data were obtained in cirrostratus cloud (bullet rosette ice crystals). 

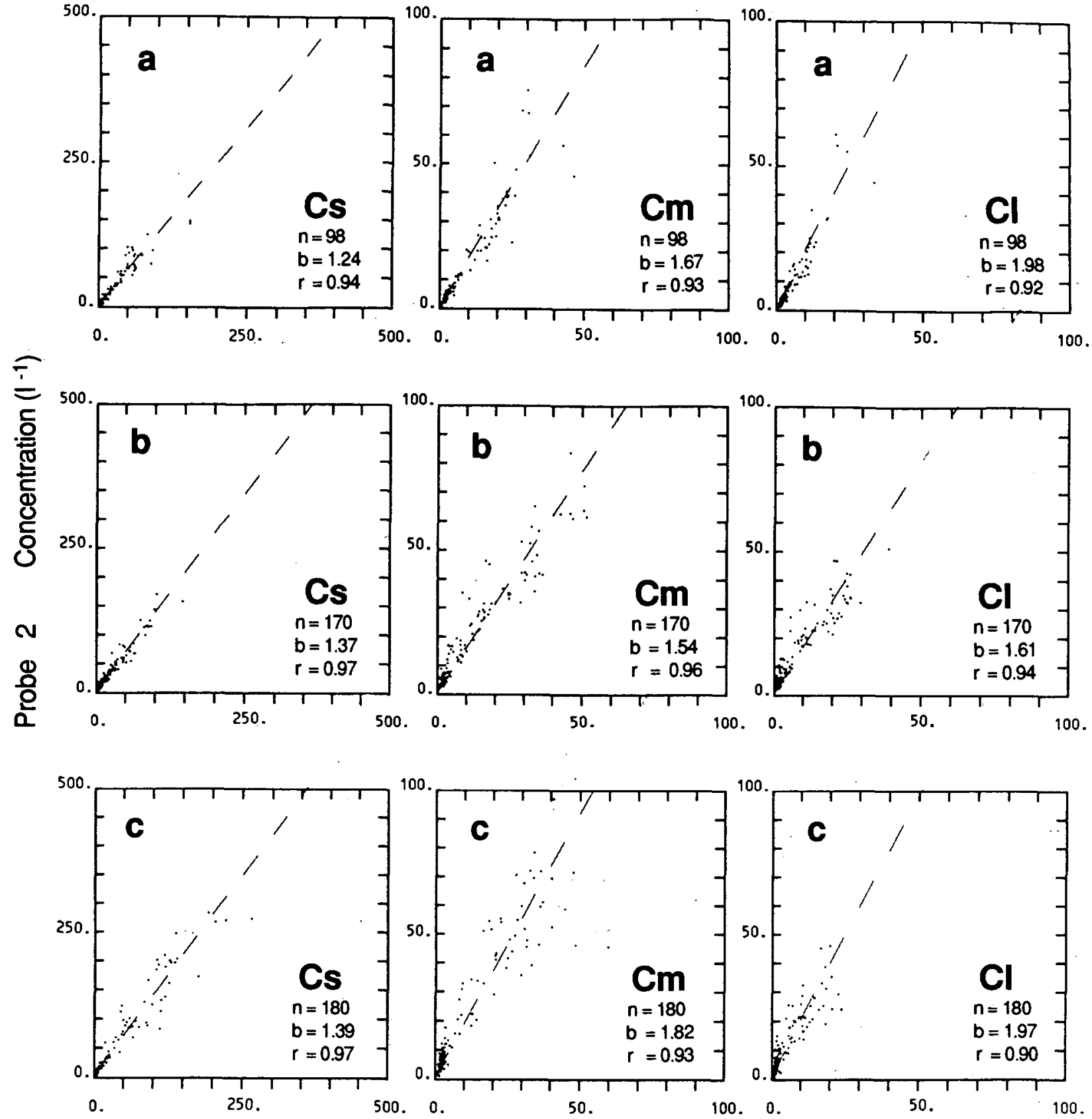

\section{Probe 1 Concentration $\left(1^{-1}\right)$}

FIG. 9. Comparison of the particle concentrations obtained from probe 2 and probe 1 for the three size ranges already defined, $\mathrm{Cs}$, $\mathrm{Cm}$, and $\mathrm{Cl}$, and three airspeed ranges: (a) from 80 to $90 \mathrm{~m} \mathrm{~s}^{-1}$, (b) from 90 to $110 \mathrm{~m} \mathrm{~s}^{-1}$, and (c) from 110 to $130 \mathrm{~m} \mathrm{~s}^{-1}$. The data were obtained at different levels $\left(+3^{\circ}\right.$ to $-35^{\circ} \mathrm{C}$ ) in an embedded convective layer (where the particle were drops and ice columns) and then in altostratus and cirrus clouds (irregular ice particles).

$<b<1.39$ ). As previously discussed, the overcounting factors for the two larger size ranges $(\mathrm{Cm}$ and $\mathrm{Cl})$ are larger, but there appears to be no airspeed dependence of these values. Similar results are found for probe 4 (2D2-C version) (see Table 4).

Figure 10 displays data obtained by probe 5 (flight 
100.
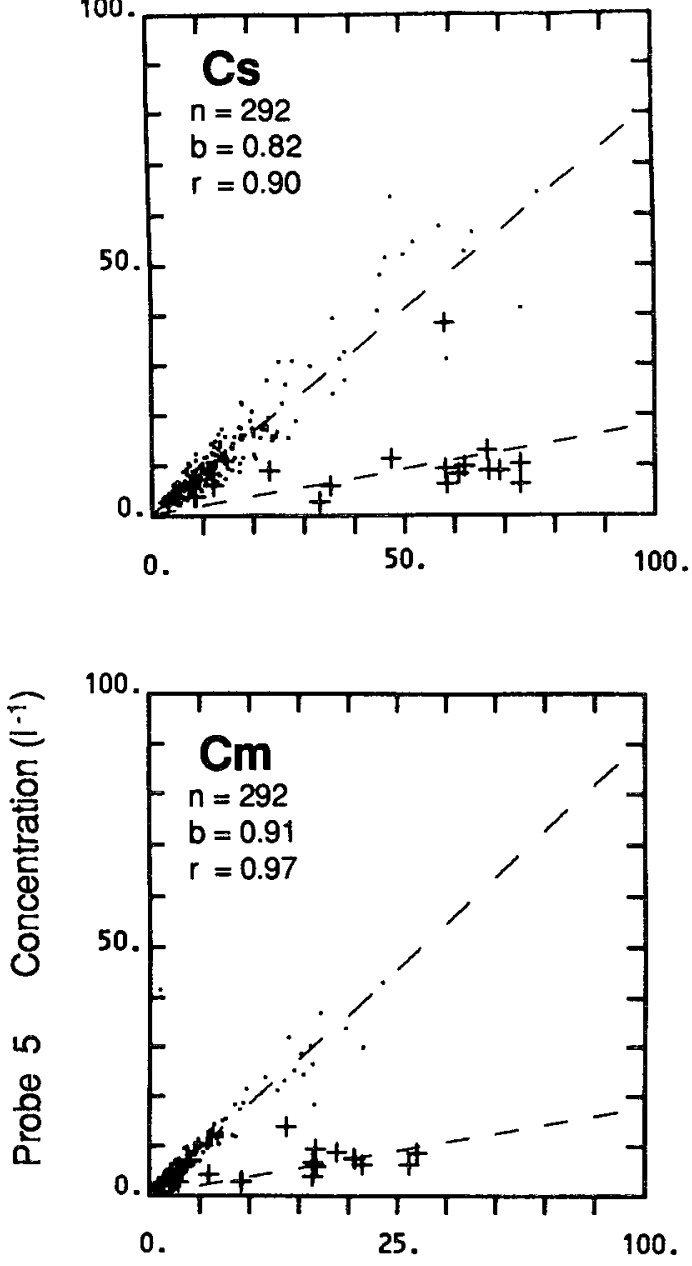

50.

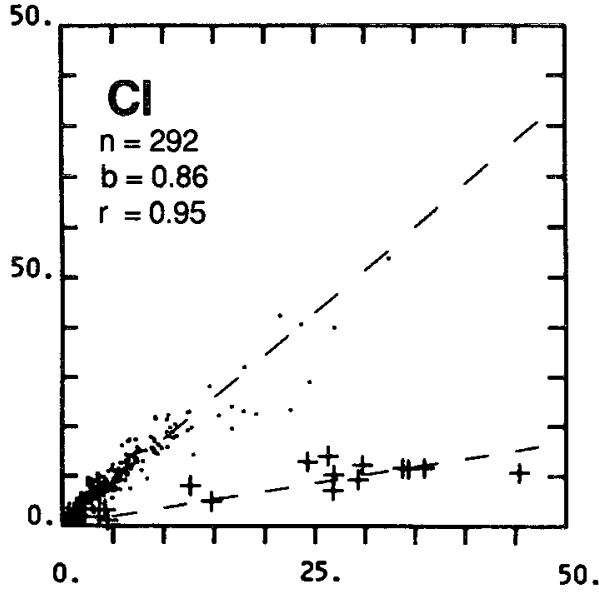

Probe 1 Concentration $\left(1^{-1}\right)$

FIG. 10. Same as Fig. 6 but with comparison of probe 5 and probe 1. The dotted points were obtained with an airspeed lower than 122 $\mathrm{m} \mathrm{s}^{-1}$; the crossed points at airspeeds above $122 \mathrm{~m} \mathrm{~s}^{-1}$.
3 ) for two ranges of airspeed greater than and less than $122 \mathrm{~m} \mathrm{~s}^{-1}$ (dot and cross symbols, respectively). For the lower range of airspeed, a close agreement (to within around $15 \%$ ) is observed between the concentrations measured by probe 5 and probe 1 . At airspeed greater than $122 \mathrm{~m} \mathrm{~s}^{-1}$, a large undercounting factor (around 5 ) is observed. This suggests that probe 5 is not reliable for airspeeds larger than about $122 \mathrm{~m} \mathrm{~s}^{-1}$. This is thought to be due to a clock-rate limitation on the shift registers that occur near $5 \mathrm{MHz}$. This characteristic was, however, observed only with this particular probe and not with probes 1 and 3 , which also employ shift registers.

Comparisons of the concentrations measured with the old version $\mathrm{P} 3$ and the reference $\mathrm{P} 1$ for the three ranges of airspeed are shown in Fig. 11. The value of the slope parameter of the smaller size concentration (Cs) decreases from 1.14 to 0.73 when the airspeed varies from 80 to $130 \mathrm{~m} \mathrm{~s}^{-1}$. As for the $\mathrm{Cm}$ and $\mathrm{Cs}$ concentration responses, they are both in good agreement $(\approx 1.04)$ for airspeeds lower than $110 \mathrm{~m} \mathrm{~s}^{-1}$ and then decrease to 0.86 and 0.94 , respectively, for a larger range of airspeed. These results confirm that the concentration response of the smallest particle size is affected by the airspeed, as reported by Baumgardner et al. (1986).

In conclusion, the concentration responses are not significantly affected by the airspeed in the range of 80 to $130 \mathrm{~m} \mathrm{~s}^{-1}$ except for the two oldest version probes, $\mathrm{P} 3$ and P5, the latter, in particular, being limited to $122 \mathrm{~m} \mathrm{~s}^{-1}$.

\section{b. Particle-size intercomparison}

\section{1) RELATIVE SIZE RESPONSE}

Figure 12 shows the mean-size spectra obtained from three probes, $\mathrm{P} 1, \mathrm{P} 2$, and $\mathrm{P} 3$, during a run of $2-\mathrm{min}$ duration in cirrostratus cloud at a true airspeed of 110 $\mathrm{m} \mathrm{s}^{-1}$ (flight 6 ). The flight-level temperature was around $-35^{\circ} \mathrm{C}$. The ice-particle population is composed mainly of broad-branched crystals (as shown in the upper-right corner of Fig. 12). All three sets of measurements are characterized by a bimodal size distribution, with identical secondary modes centered around $200 \mu \mathrm{m}$. This suggests that the particle-size response (after the image processing) of each probe is nearly identical within the resolution of the device, that is, $25 \mu \mathrm{m}$.

Figure 12 also illustrates the concentration differences between each probe already discussed in the previous section. These differences are emphasized in Fig. 13 , which represents the ratio of $\mathrm{P} 2 / \mathrm{P} 1$ and $\mathrm{P} 3 / \mathrm{P} 1$ concentrations as a function of the diameter. The results show a response factor that is different for the two probes but in each case is roughly independent of particle size in the range $75-500 \mu \mathrm{m}$ (varying by less than 

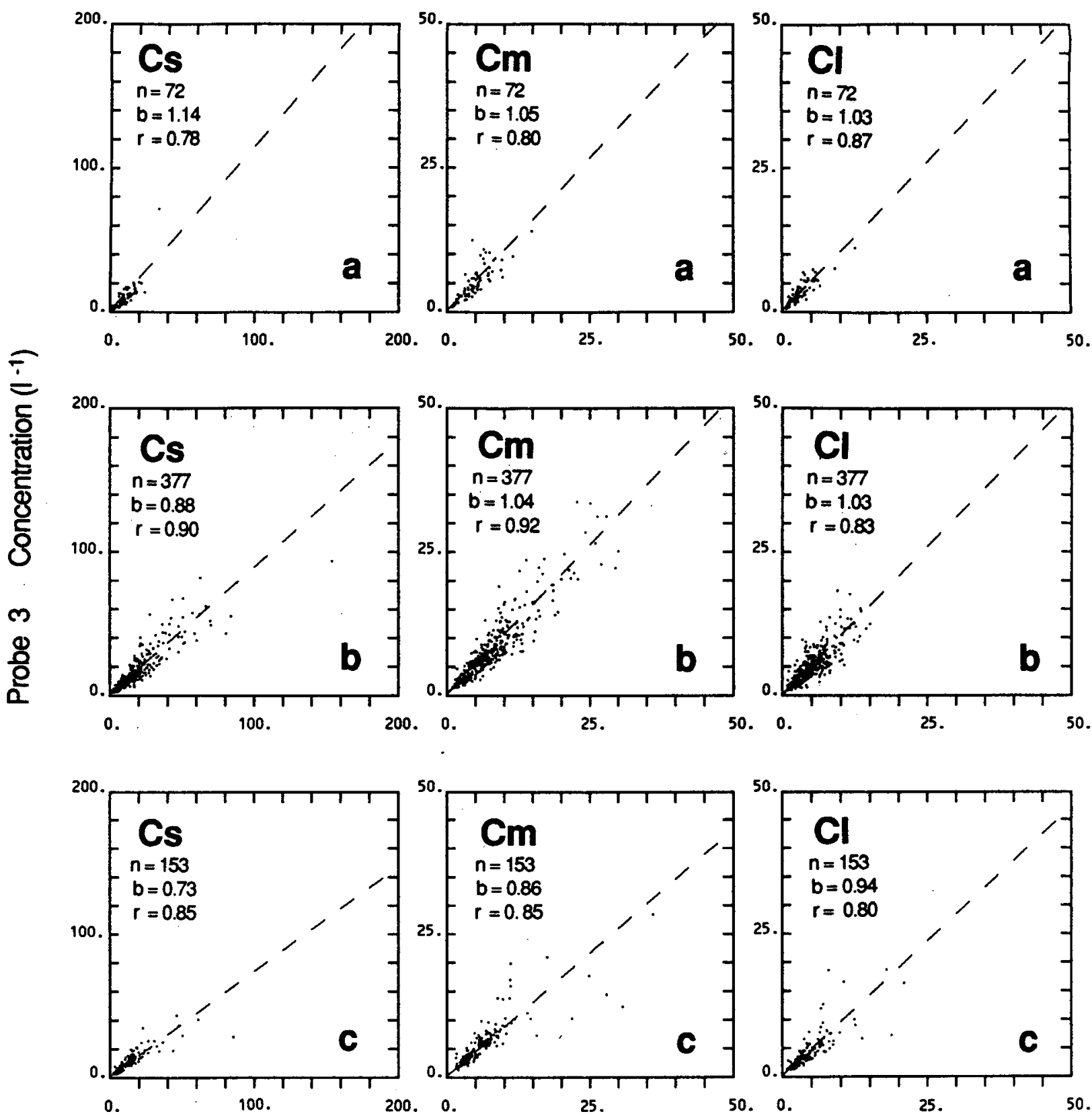

\section{Probe 1 Concentration $\left(l^{-1}\right)$}

FIG. 11. Same as Fig. 9. Probe 3 against probe 1. Data obtained in cirrostratus cloud (irregular ice particles).

$25 \%$ ). For larger particle sizes, the ratios are not statistically significant due to the small numbers of particles sampled in each channel.

\section{2) MEAN VOLUME PARTICLE-SIZE RESPONSE}

Whereas the previous paragraph concerned the ability of each probe to correctly identify a gross feature of the size distribution, namely, the mode, the mean volume size ( Dv) concerns the ability to measure a property of the overall shape of the size spectrum. The mean volume size is defined so that half of the liquid or ice water content is contained in particles larger than Dv and half in particles smaller than Dv.

The regression parameters for the Dv measurements of each $2 \mathrm{D}-\mathrm{C}$ probe relative to the reference probe 1 


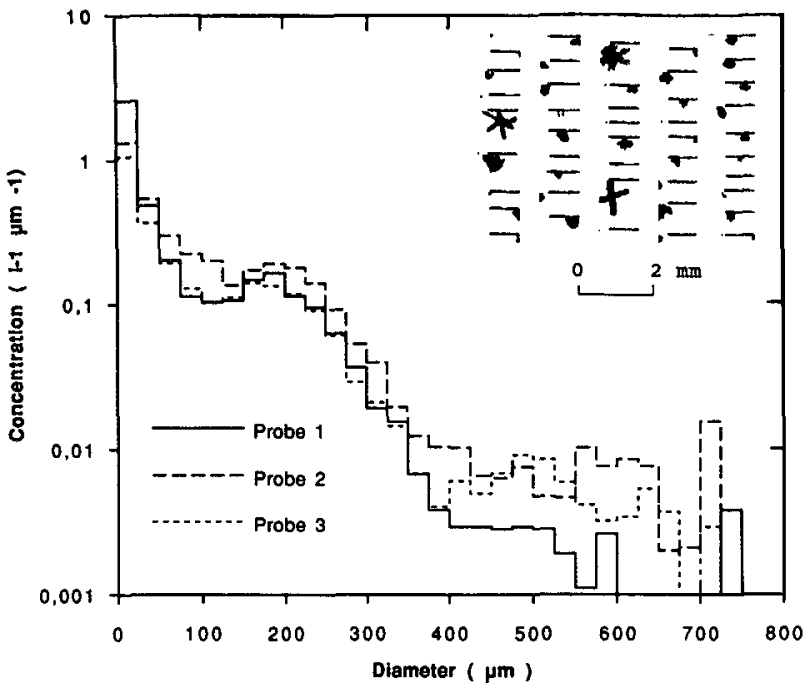

FlG. 12. Particle-size spectra obtained from simultaneous measurements by three different PMS 2D-C probes for a 2-min segment in a cirrostratus cloud. An example of corresponding sampled icecrystal habits is shown in the upper-right corner of the figure.

for the three ranges of airspeed earlier considered are summarized in Table 4. For an airspeed of around of $100 \mathrm{~m} \mathrm{~s}^{-1}$ and for any probe, linear relationships are also observed between the two Dv measurements with correlation coefficients generally larger than 0.80 . The results show that the slope parameters are close to unity (to within about $10 \%$ ) for each probe considered. The intercept parameters $a_{0}$ that reflect offset errors are less than the size resolution of the device, that is, $25 \mu \mathrm{m}$. Figure 14 illustrates one example of mean volume size

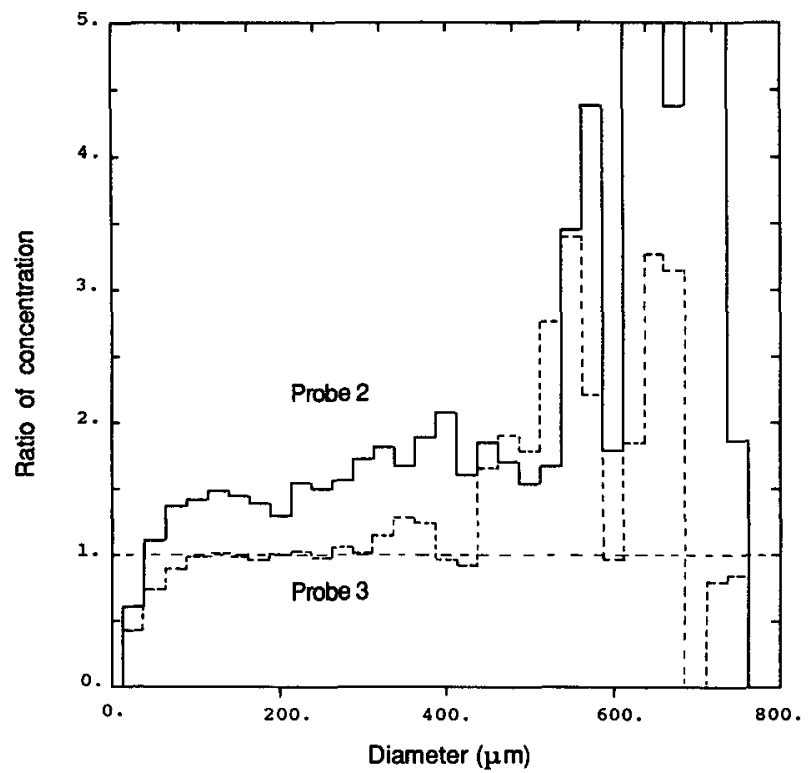

FIG. 13. Ratio of the concentrations $\mathrm{P} 2 / \mathrm{P} 1$ and $\mathrm{P} 3 / \mathrm{Pl}$ as a function of the diameter, from the same data as to the Fig. 12 results.

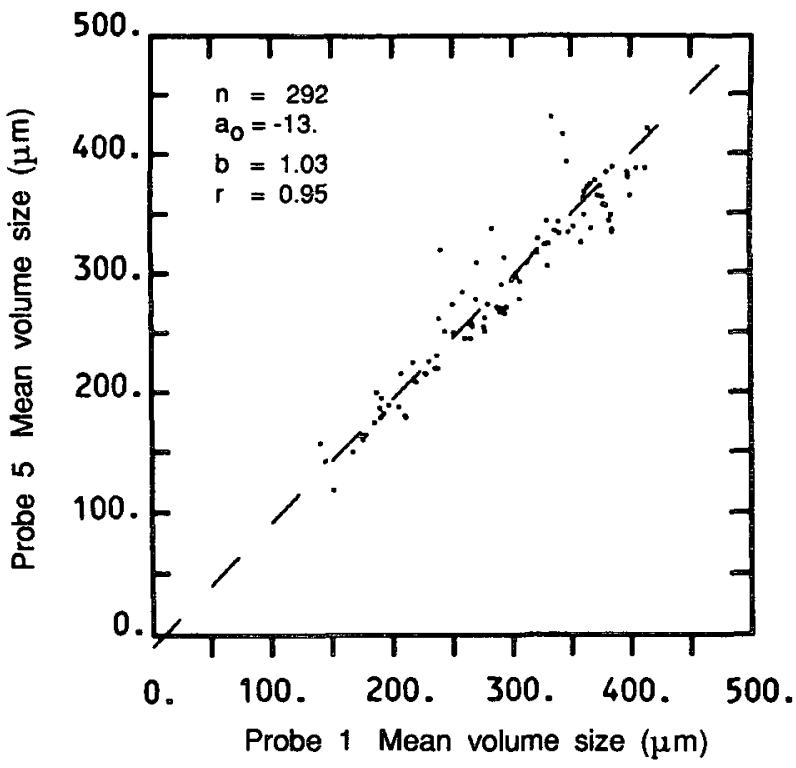

FIG. 14. Comparison of the particle mean volume size obtained from probe 5 and probe 1 at an airspeed of $100 \mathrm{~m} \mathrm{~s}^{-1} \pm 10 \%$. The data were sampled in a cirrostratus cloud (bullet rosette crystals).

intercomparison using the data from probe 5 , relative to the reference probe 1 . These data were obtained at a temperature of $-37^{\circ} \mathrm{C}$ in cirrostratus cloud, where the sampled ice particles were mostly bullet rosette crystals (flight 3 ). This example is representative of comparisons involving all the probes used in this study.

The results in Table 4 also suggest that the airspeed has no significant effect on the size response. We can therefore conclude that the mean volume particle size is measured to an accuracy of around $10 \%$ relative to the reference probe over the whole range of airspeeds and particle habits over which measurements were made.

\section{Discussion}

From the statistical intercomparisons presented in the preceding sections, the following main points may be identified.

1) The coefficient of variation of concentration measurements does not change significantly with increasing concentration, mean values of around $25 \%$ being obtained for all probes. This coefficient, which reflects random errors about the best-fit line through the data, may therefore be attributed to the measurement errors in the instruments compared and, to a lesser extent, to the natural cloud concentration fluctuations. (Identical cloud lengths are sampled by each probe compared.)

2) Differences in the slope of the best-fit line from unity may be interpreted in terms of systematic errors such as malfunctioning of the instruments. Depending on the probe considered, a wide range of discrepancies 
in particle concentration measurements relative to those obtained from the reference probe are observed. These correspond to overall relative errors of up to $50 \%$ and produce both undercounting and overcounting relative to the reference probe.

When considering the two new version probes P2 and $\mathrm{P} 4$, both overestimate the concentration with a factor of around 1.5 relative to probe 1 . The concentration response of the other new version probe (P6) is significantly different and appears to give good agreement with the reference probe. Nevertheless, a careful examination of the raw images issued from the probe 6 shows a loss of pixels in the image digitization (see examples of such images on Fig. 15). This problem of digitization may affect the sizing and therefore lead to an underestimation of concentrations if no subsequent size corrections are made. The reason for the observed loss of image pixels may be explained by a power loss in the laser that results in a low signal-tonoise ratio at the photodetector module. Unfortunately, no further laboratory investigations were made on this probe during the PREICE experiment, and it was tested only during one flight (flight 3 ).

As for the concentration responses of probes 5 and $\cdot 3$, they are found to be in a rather good agreement with the reference probe 1 (to within about 15\%). These three probes are of a similar version (2D-C).

From the preceding discussion, the observed discrepancies in particle concentrations made by the different probes seem to be related primarily to the probe version. There are several differences between the two types ( see Table 1). It has already been noted that the mechanical and optical characteristics of these two versions are identical. By contrast, there are two main electronic differences.

1) The response time of the photodetectors in an old model probe was found to be significantly longer than the newer model [ 1.0 and $0.3 \mu \mathrm{s}$, respectively; Albers (1989)]. It would be expected to affect primarily the smaller size channels (and the subsequent sample

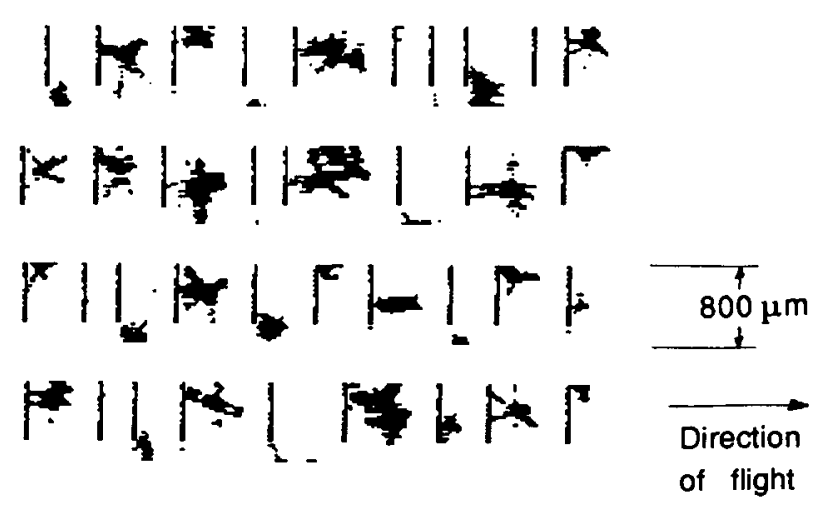

FIG. 15. Example of images sampled by probe 6 during flight 3 showing the problem of loss of pixels in the image digitization. volumes), causing a greater degree of undersizing than for larger particles, as shown theoretically by Baumgardner et al. ( 1986). These authors also proposed airspeed corrections on size and sample volume to account for electronic response-time problems. Relative size dependency of the measurement discrepancies, however, was not generally observed, particularly for the smaller size channels, and most of the discrepancies in concentration are predominantly size independent (i.e., Figs. 12 and 13 ).

2) In 2D2-C probe the image slices are stored via a random access memory (RAM) that operates faster than the shift registers used in the old version. Examination of the raw data simultaneously obtained by two probes (new and old versions, P4 and P1, respectively) has shown that the buffers of probe 4 contain approximately $50 \%$ more images larger than $200 \mu \mathrm{m}$ than do the buffers of probe 1 . The reason why this apparently results in 50\% larger particle-concentration measurements, however, is not clear.

The determination of the sampling area may also be a source of probe discrepancies. The sample volume of the probe is the product of the sampling area and sample duration. The sample area is dependent on the particle size, and hence, any errors in its evaluation will be likely to produce size-dependent errors in concentration. The sample duration is the nominal averaging period minus any periods for which the probe was overloaded and therefore not recording images. Any errors in the measurement or processing of the overload time will produce errors in the sample volume.

In conclusion, the discrepancies in particle-concentration measurements appear to be related primarily to the differences between old and new probe versions through the use of updated, faster electronics in the latter. These effects on measurements appear difficult to separate and to quantify from airborne data such as described in this study, given the uncertainties that were noted earlier in defining the probe depth of field for particles smaller than $150 \mu \mathrm{m}$. In order to quantify the latter, it may be necessary to plan laboratory experiments similar to those performed on forward-scattering spectrometer probes (FSSPs) (see, among others, Cerni 1983) and wet wind-tunnel tests, such as described by Gayet (1988).

\section{Other sources of uncertainty to be considered}

We have emphasized in the previous section that several combined sources of error may explain the noticeable differences in concentration measurements when comparing several instruments. Additional sources of error inherent to the probe working may also be evidenced by testing different methods of determining the sampling-time duration. The method of data processing used for data earlier in this paper determines the sampling time as $t_{\mathrm{sa}}=t_{\mathrm{end}}-t_{\mathrm{start}}-t_{\mathrm{ov}}$, 
where $t_{\text {start }}$ and $t_{\text {end }}$ are the start and end times of the image buffer and $t_{\mathrm{ov}}$ is the overload time that is recorded for each separate buffer. These time parameters are issued from the aircraft DAS. The sampling time can also be taken (for a single image buffer) as the sum of the interimage elapsed times $t_{\mathrm{sb}}$. The interimage elapsed times are provided by the probe.

Both of these methods for determining the sampling time were used on a dataset obtained from a single probe (P6 during flight 3 ). Figure 16 shows the comparison of concentration measurements obtained with the two methods for particle larger than $100 \mu \mathrm{m}$ (the airspeed is around $110 \mathrm{~m} \mathrm{~s}^{-1}$ ). The results show two distinct responses for different data points. At some times there is a close agreement between the two methods, and on other occasions there is a significant undercounting when using $t_{\mathrm{sb}}$. The discrepancies, which are solely due to differences in the two sampling time durations (with $t_{\mathrm{sb}}$ much greater than $t_{\mathrm{sa}}$ ), have been found to be due to sporadic error in the coding of the elapsed times between individual images generated by probe 6 [ full 24-bit time bar; Albers (1991)]. This clearly appears in Fig. 17, which shows the distribution of the interelapsed time intervals obtained in the conditions of Fig. 16. The marked peak that occurs at a sampling time of $4.2 \mathrm{~s}$ is spurious and leads to large errors on concentration measurements. When the spuriously large elapsed times that occur between some images are rejected, the two methods of sample time determination are found to give very similar results to those shown in the good-agreement area in Fig. 16.

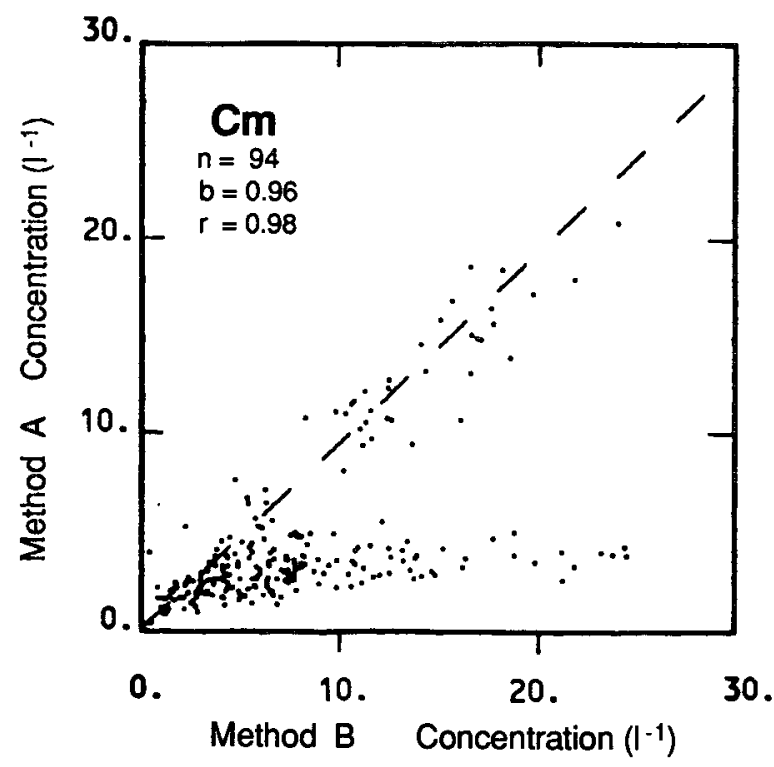

FIG. 16. Comparison of the particle concentration obtained from probe 6 by using two methods of sampling-time determination (A and $B$ ) and for the particles larger than $100 \mu \mathrm{m}(\mathrm{Cm})$. The regression parameters are calculated only for measurements having a correct coding of the time parameters. Irregular ice particles were sampled (flight 6), and the airspeed is about $110 \mathrm{~m} \mathrm{~s}^{-1}$.

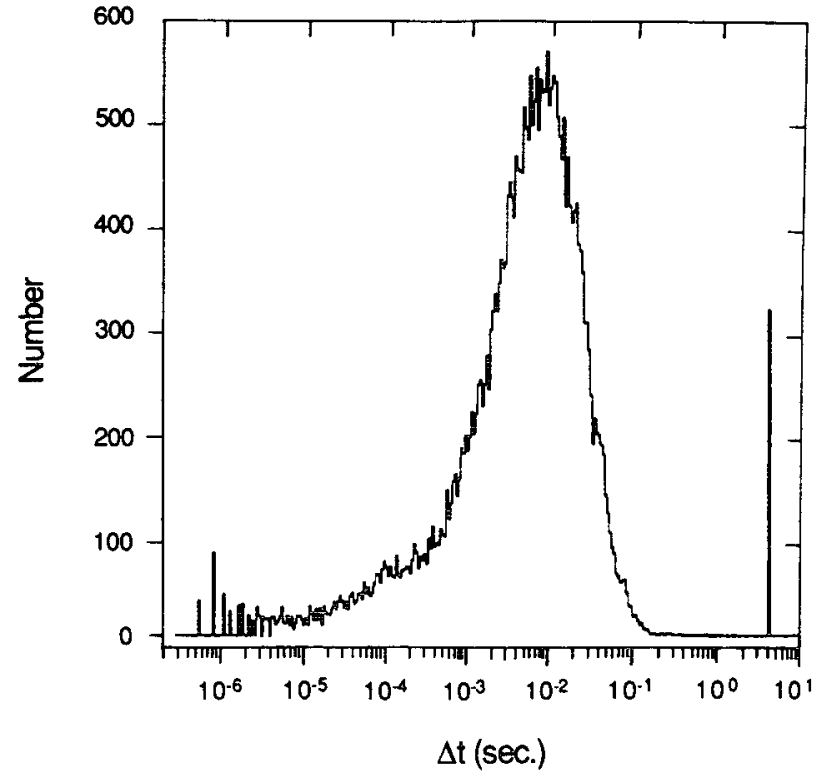

FIG. 17. Distribution of the interimage elapsed times measured by probe 6 during the flight 6 (from Albers 1991).

The relative discrepancies evidenced in previous sections will obviously be reflected in measurements of derived cloud microphysical quantities, such as ice water content (IWC) or visible extinction coefficient $\sigma$. As is usually the case, the particle shapes found in the atmosphere do not correspond to any of the pure crystal types found in textbooks. Consequently, the 2D data-processing methods ( see the review of Heymsfield and Baumgardner 1985) cannot classify the more irregularly shaped images introducing inherent errors in the size-mass relationships (Darlison and Brown 1988). Furthermore, the use of different software packages, as developed by each participating organization, can also introduce differences in measurements that have a similar magnitude as those evidenced in this study (Gayet et al. 1990). Attempts are being made to estimate IWC separately from measurements of the size spectrum, using a total water content probe (Brown 1993). The magnitude of errors in these direct integrated measurements is currently quite large, but it appears that such methods may have some benefit in identifying gross errors in 2D probe measurements, whether the latter are caused by software or hardware problems.

\section{Conclusions}

During the PREICE experiment, six different 2D-C probes were tested and compared. Three of these probes were new versions (2D2-C); the others were original instruments (2D-C version). From a systematic analysis of all the data obtained in a variety of glaciated and unglaciated clouds, the following conclusions may be drawn. 
1) The use of different external mounting points on the aircraft and the use of two different DAS's generate uncertainties that are small compared to those associated with the individual probes themselves.

2) The mode sizes measured by all probes agree to within the nominal resolution $(25 \mu \mathrm{m})$. Mean volume sizes differ by less than $10 \%$ for the whole range of airspeeds and particle habits encountered in this study.

3) The concentration response factors are roughly linear over the range of concentrations considered $\left(<250 \mathrm{l}^{-1}\right)$, with random errors of about $25 \%$. These response factors were found to be generally independent of the airspeed, up to $130 \mathrm{~m} \mathrm{~s}^{-1}$, except for the two oldest probes.

4) Individual probes show large relative differences in particle-concentration measurements of up to a factor of about 1.5. These differences are predominantly size independent and are found to be linked to the probe version. The $2 \mathrm{D} 2-\mathrm{C}$ probes appear to detect around $50 \%$ more images than the $2 \mathrm{D}-\mathrm{C}$ instruments. These differences are related to the faster electronic circuitries of the updated version. Some of the discrepancies between individual probes, however, are due to the uncertainty in the definition of the depth of field. There is a need for both laboratory experiments and wet wind-tunnel studies in order to quantify these errors for a wide range of cloud characteristics and airspeeds.

5) The use of two different methods of calculating the sampling duration showed that additional sources of errors could result from probe timing malfunctions. Without subsequent software corrections, the effect can lead to unreliable concentration measurements.

These results will be used to assess the relative accuracy of microphysical measurements obtained during the major field phase of the ICE experiment. It is hoped that a common data processing scheme will be employed. Due to fundamental differences between the types of data recording systems used on each of the aircraft employed in the main experiment, however, unavoidable differences will remain. The PREICE experiment illustrates that a considerable amount of care is necessary when comparing measurements made during multiaircraft experiments.

Acknowledgments. We are very grateful to the CAM group who operated the Merlin aircraft and helped us in perfecting and installing the 2D data acquisition systems. We thank the Etablissement d'Etudes et de Recherches de la Météorologie Nationale for allocating flight hours. We particularly wish to thank Christophe Duroure and Jean-François Fournol (LaMP) for valuable discussions. We thank Darrel Baumgardner (NCAR) and anonymous reviewers for their helpful comments. We also thank Markus Quante (GKSS), Michel Soulage, and André Gribkoff (INSU) for their active participation in the experiment. This work was supported under Contract INSU 883624.

\section{REFERENCES}

Albers, F., 1989: Flugzeugmessungen der Eiskristallkonzentration und-größenverteilung mittels optisch abbildender Sonden in Cirrus-Wolken. M.S. thesis. University of Cologne, Institute for Geophysics and Meteorology, $85 \mathrm{pp}$.

, 1991: Improvement for the analysis of 2D probe data. Report of the fourth Workshop of the International Cirrus Experiment. Reading, United Kingdom, [Report available at GKSS, Geesthacht, Federal Republic of Germany.]

Baumgardner, D., 1983a: Airflow induced rotation of ice particles. NCAR Newletter, Division Airborne of Cloud Physics Instrumentation.

$-, 1983 \mathrm{~b}:$ An analysis and comparison of five water droplet measuring instruments. J. Climate Appl. Meteor., 22, 891-910.

, J. E. Dye, and W. A. Cooper, 1986: The effects of measurements uncertainties on the analysis of cloud particle data. Preprints 23th Conf. on Radar Meteorology and Cloud Physics. Snowmass, Co, 313-316.

Brown, P. R. A., 1993: Measurements of the ice water content of cirrus using an evaporative technique. J. Atmos. Oceanic Technol., 10, in press.

Cerni, T. A., 1983: Determination of the size and concentration of cloud drops with an FSSP. J. Climate Appl. Meteor., 22, 13461355.

Cox, S. K., 1973: Cirrus clouds and the climate. J. Atmos. Sci., 28, 1513-1515.

Darlison, A. G., and P. R. A. Brown, 1988: The use of automatic particle recognition to improve the determination of bulk quantities from PMS 2-D probe data in cirrus. Preprints, 10th Int. Cloud Physics Conf., Bad Homburg, Federal Republic of Germany, 138-140.

Gayet, J.-F., 1988: Calibration of PMS FSSP and 1D-C probes for cloud droplet measurements. Proc. Int. Conf. on Cloud Physics, Bad Homburg, Federal Republic of Germany, 325-327.

- P. A. Brown and F. Albers, 1990: Results of the PREICE Experiment. 42 pp. [Report available from LaMP. University Blaise Pascal, Clermont-Ferrand, France.]

Gordon, G. L., and J. D. Marwitz, 1984: An airborne comparison of three PMS probes. J. Atmos. Oceanic Technol., 1, 22-27.

Guillemet, B., 1990: Thermodynamical and dynamical measurements on Merlin-IV-GMTO and Fokker-27 ARAT aircraft. Workshop on Improvements to Aircraft Instrumentation for the Measurements of Cirrus Clouds. Reading, United Kingdom. [Report available at Meteorological Research Flight, Farnborough, United Kingdom ].

Heymsfield, A., and D. Baumgardner, 1985: Summary of a workshop on processing 2-D probe data. Bull. Amer. Meteor. Soc., 66, $437-440$.

King, W. D., 1984: Air flow and particle trajectories around aircraft fuselages. Part I: Theory. J. Atmos. Oceanic Technol., 1, 5-13.

Knollenberg, R. G., 1970: The optical array: An alternative to scattering or extinction for airborne particle size determination. $J$. Appl. Meteor., 9, 86-103.

MacPherson, J. I., and D. Baumgardner, 1988: Airflow about King Air wingtip-mounted cloud particle measurement probes. J. Atmos. Oceanic Technol., 5, 259-273.

Nicholls, S., J. Leighton, and R. Barker, 1990: A new fast response instrument for measuring total water content from aircraft. $J$. Atmos. Oceanic Technol., 7, 706-718.

Raschke, E., J. Schmetz, J. Heintzenberg, R. Kandel, and R. Saunders, 1990: The International Cirrus Experiment (ICE) - A joint European effort. ESA J., 14, 193-199.

Slingo, A., 1990: Sensitivity of the Earth's radiation budget to changes in low clouds. Nature, 343, 49-51.

Stephens, G. L. and P. Webster, 1981: Clouds and climate: Sensitivity of simple systems. J. Atmos. Sci., 38, 235-247.

, S-C Tsay, P. W. Stackhouse, Jr., and P. J. Flatau, 1990: The relevance of the microphysical and radiative properties of cirrus clouds to climate and climatic feedback. J. Atmos. Sci., 47, 17421753. 